This is the post-print version of a paper published in Sciencia Horticulturae. The publisher's version can be downloaded here:

http://www.sciencedirect.com/science/article/pii/S0304423816304277

DOI:

http://dx.doi.org/10.1016/j.scienta.2016.08.028

Cite as:

L. Perera, L. Baudouin and I. Mackay 2016. SSR markers indicate a common origin of selfpollinating dwarf coconut in South-East Asia under domestication. Scientia Horticulturae 211:255-262.

Licence: (CC BY-NC-ND)

\title{
SSR markers indicate a common origin of self-pollinating dwarf coconut in South-East Asia under domestication
}

Lalith Perera $^{1}$, Luc Baudouin ${ }^{2}$ and Ian Mackay ${ }^{3}$

${ }^{1}$ Genetics \& Plant Breeding Division, Coconut Research Institute, Sri Lanka (lalithperera1234@yahoo.com)

${ }^{2}$ CIRAD, UMR AGAP, F-34398 Montpellier, France (luc.baudouin@ @irad.fr)

${ }^{3}$ National Institute of Agricultural Botany (NIAB), Cambridge, UK (ian.mackay@niab.com)

Corresponding author: Lalith Perera (lalithperera1234@yahoo.com)

\begin{abstract}
The commercial cultivation of dwarf coconut is rare in the world, representing about $5 \%$ of global population. However, Dwarfs are currently receiving more attention, particularly for the harvest of tender nut water. Dwarfs are distinguished from tall coconuts primarily by their short height with an absence of a bole at the base of the stem, their early setting of nuts, their predominantly self fertilizing mating system and by large numbers of relatively small nuts. To date, the origin and domestication of Dwarfs has not been established. This study investigates the origin and domestication of dwarf coconut using molecular markers, mainly microsatellite (SSR) data. The inheritance of height and the presence of a bole was investigated in the $F_{2}$ of a cross between Dwarf and Tall palms. The data suggest that the presence of a bole results from a single codominant locus. There was no strong association between the presence of a bole and height, with height also depending on a single codominant gene. However genetic and environmental factors make it difficult to assign individuals a definite genotype. SSR allele frequency differences between dwarf and tall accessions, ethno botanical and geographic information indicate that dwarf coconut originated from a typical domestication event in Southeast Asia.
\end{abstract}


Key words: Coconut, Dwarfism, Genetic inheritance, Domestication, Microsatellites

\section{Introduction}

The most popular classification of coconut is based predominantly on height and pollination behaviour, resulting in two broad categories; Tall and Dwarf coconuts, also known as-'typica' and 'nana' respectively (Menon and Pandalai, 1958). Tall coconut is widely grown commercially. It is fast growing, has a swelling (a bole) at the base of the stem, bears fruit late, thrives in diverse environments, produce medium to large nuts and is predominantly outcrossing. However, self-pollination (geitonogamy) through inter-spadix pollination has been observed in some Tall populations (Bourdeix 1988; Bourdeix et al. 1990, unpublished data in Sri Lanka).

Dwarf coconuts represent about 5\% of global population and are usually found close to habitation. They share a number of characteristics which distinguishes them from Talls; short internodes, slow growth in height, predominant self-pollination, short leaves with a small number of leaflets, large numbers of relatively small fruits, early fruit set and a relatively short life span. Most Dwarfs have no bole and their nuts have a sweet and pleasant- to-drink water (liquid endosperm). Dwarfs are diverse for a small number of traits such as colour and appearance of the nut, shape of the inflorescence and of the crown. It is worth noting that the Niu Leka Dwarf coconut, with its short stature and short leaves has a markedly different phenotype, often called "compact Dwarf" to differentiate it from the usual Dwarfs. It is an out-breeder and the phenotype is dominant. In this paper we deal only with the selfpollinating Dwarfs.

Dwarf coconut is usually cultivated in small numbers close to houses. It is appreciated for its short stature and for the sweet and pleasant taste of its coconut water. Due to below average copra quality and yield it is rarely grown commercially for oil production though it is increasingly planted on a large scale for coconut water production, especially in Brazil. It is also used to produce commercial $\mathrm{F}_{1}$ Dwarf $\mathrm{x}$ Tall hybrids. These are produced by emasculating the inflorescences of Dwarf coconuts planted in isolation and applying pollen from selected Talls (De Nucé De Lamothe and Rognon 1973). Alternatively, a few Tall coconuts can be inter-planted with Dwarfs for natural pollination. Compared to their parents, the phenotype of the hybrids is intermediate, though with a tendency to resemble the Tall parent for presence of bole, height, growth rate, reproductive pattern and fruit size, but to resemble the Dwarf for precocity and fruit number (De Nucé De Lamothe and Rognon 1973). Height, time to fruit and pollination behaviour segregates independently in the $F_{2}$ (Fernando and Perera 1997).

The origin and genetic control of dwarfism has been discussed (Ninan and Satyabalan 1964) but is sometimes obscured by imperfect control of pollination. Swaminathan and Nambiar (1961) suggested that Dwarf coconuts originated as a result of inbreeding Talls. Purseglove (1985) stated that Dwarfs were mutations while Harries (1978) included the Dwarfs in the "domesticated" coconut type based on traits such as early germination, precocity, distinctive bright fruit colour, the proportion of husk to nut, and for some forms the high degree of resistance to lethal yellowing disease. However, to date no conclusive evidence has been presented about the origin and domestication of Dwarfs. This study investigates the origin of Dwarf coconut and its domestication. 


\section{Material and methods}

\subsection{Place of Dwarfs within coconut diversity}

To study diversity and among Tall and Dwarf coconuts, we calculated allele frequencies at 12 microsatellite loci (CAC2, CAC3, CAC4, CAC6, CAC8, CAC10, CAC13, CAC20, CAC52, CAC56, CAC65, CAC68) using ARLEQUIN (Version 1.0) for 51 Tall and 43 Dwarf coconut varieties. These were collected from all over the world based and are described in Perera $e t$ al. (2003). The PCR conditions were as follows: denaturing at $94{ }^{\circ} \mathrm{C}$ for $3 \mathrm{~min}$, annealing at $65{ }^{\circ} \mathrm{C}$ for $1 \mathrm{~min}$ followed by a seven-step touchdown decreasing by $1{ }^{\circ} \mathrm{C}$ at each step to $58{ }^{\circ} \mathrm{C}$ and an extension step at $72{ }^{\circ} \mathrm{C}$ for $2 \mathrm{~min}$. Conditions for the final 27 cycles were $94{ }^{\circ} \mathrm{C}$ for 1 $\min , 58{ }^{\circ} \mathrm{C}$ for $1 \mathrm{~min}$ and $72{ }^{\circ} \mathrm{C}$ for $2 \mathrm{~min}$. PCR was performed in a total volume of $20 \mu \mathrm{l}$ containing $1 \mathrm{x}$ PCR buffer (10 mM Tris-HCl, $1.5 \mathrm{mM} \mathrm{MgCl} 2,50 \mathrm{mM} \mathrm{KCl}, \mathrm{pH} 8.3), 200 \mathrm{mM}$ dNTPs, 10 pmol ${ }^{32} \mathrm{P}$ end-labeled forward primer, 10 pmol reverse primer, $0.1 \mathrm{U}$ Taq polymerase and $20 \mathrm{ng}$ of genomic DNA. Reaction products were separated on $6 \%$ polyacrylamide gels in $1 \mathrm{x}$ TBE buffer and visualized by autoradiography. A standard M13 sequence reaction was run with each primer pair for the purpose of accurate allele sizing.

\subsection{Microsatellite diversity among Dwarfs}

We analyzed 246 individuals representing 28 Dwarf varieties (Table 1) with 13 microsatellite markers (CnCirA3, CnCirA9, CnCirB6, CnCirB12, CnCirC7, CnCirC12, CnCirE2, CnCirE10, CnCirE12, CnCirF2, CnCirG11, CnCirH4' and CnCirH7). The SSR analyses were performed on an automatic sequencer Li-Cor IR2 (Lincoln, Nebraska). For each SSR locus, one of the primers was designed with a 5'-end M13 extension. For the PCR amplification, 25 ng of DNA was used in a $10 \mu \mathrm{l}$ final volume, containing $0.08 \mu \mathrm{M}$ of the M13 labeled primer, $0.1 \mu \mathrm{M}$ of the other primer and $0.06 \mu \mathrm{M}$ of M13 primer-fluorescent dye IR700 or IR800 (Biolego, The Netherlands). The PCR mix contained 1 x Buffer $(10 \mathrm{mM}$ Tris- $\mathrm{HCl} \mathrm{pH} 8,50$ $\mathrm{mM} \mathrm{KCl}$ and $2 \mathrm{mM} \mathrm{MgCl} 2), 200 \mu \mathrm{M}$ DNTP and $1 \mathrm{U}$ Taq DNA polymerase. The PCR program started with an initial denaturation at $94{ }^{\circ} \mathrm{C}$ for $5 \mathrm{~min}$, then 35 cycles of $94{ }^{\circ} \mathrm{C}$ for 30 $\mathrm{s}, 51{ }^{\circ} \mathrm{C}$ for $1 \mathrm{~min} 15 \mathrm{~s}$ and $72{ }^{\circ} \mathrm{C}$ for $1 \mathrm{~min} 30 \mathrm{~s}$, and stopped after a final elongation at $72{ }^{\circ} \mathrm{C}$ for 5 min. Each mix of the PCR products contained one or two IR700 and IR800 labeled M13 reverse complement extensions, diluted to one-fourth with formamid blue; $0.8 \mu \mathrm{l}$ of the final mix was loaded on a $6.5 \%$ polyacrylamide gel and then detected by the IR fluorescence scanning system of the sequencer (Baudouin et al. 2006).

Data on markers and genotypes are publicly available in TropGENE DB (http://tropgenedb.cirad.fr/tropgene/JSP/index.jsp). Data were analyzed by computing the pairwise Euclidean distance for each locus and summing over all loci. This ensures that the distance between completely homozygotes varieties is equal to the number of allele substitutions. The results are presented in the form of a weighted neighbour joining dendrogram using DARwin 6.0.4 (Perrier and Jacquemoud-Collet 2006).

\subsection{Height measurements}

To study the inheritance of height and the presence of bole (an enlargement at the base of the stem), we measured the distribution of these traits in 43 years old seventy individuals of a $F_{2}$ 
population derived from the $\mathrm{F}_{1}$ between Sri Lanka Green Dwarf and Sri Lanka Tall, planted at Bandiripuwa estate, Lunuwila, Sri Lanka. Palms were classified as having no bole, low bole and high bole based on the size, shape and height of the bole (figure 1). The palm height was measured from the ground level to the base of the oldest living frond (Santos et al. 1996).

\section{Results}

\subsection{Place of Dwarfs in the global coconut diversity}

The allele frequencies for each locus and each group (Tall and Dwarf) are presented in Table 2. The allele frequency distributions of Talls and Dwarfs at locus CAC2 is presented in Figure 2. The Dwarfs have reduced numbers of alleles with only 42 alleles out of a total of 85. Only one of these alleles (from CAC8) was not observed in Talls (Table 2). In many cases, the most frequent allele was the same for both Tall and Dwarf: CAC2, CAC3, CAC4 (186bp), CAC6, CAC10, CAC13, CAC52 and CAC65). This is however not always the case and at four loci the most frequent allele in the Dwarf was rare in the Talls: CAC4 (212bp), CAC8, CAC20 and CAC56. Conversely, at two loci the most frequent alleles of the Tall were not present in the Dwarfs: CAC8 and CAC68. A On splitting the Talls into Indo-Atlantic and Pacific groups, the Dwarfs share 43 alleles with the latter but only 22 with the former, out of a total of 43 alleles.

Figure 3 reproduces the neighbour joining dendrogram of Perera et al. (2003) using the same 51 Tall and 43 Dwarf varieties. showing two main and distinctive clusters of Tall coconuts (Perera et al., 2003), Oone consists of all Tall ecotypes sampled from Southeast Asia and the Pacific and the other consists of samples collected from South Asia and Africa (corresponding respectively to the Pacific and Indo-Atlantic groups of Gunn et al., 2011). All Dwarf varieties from both regions are embedded in the Southeast Asian and Pacific cluster. Most are grouped in a single sub-cluster (except for Banigan, Benga, Kinabalan, Aromatic Green, and Sto. Nino Green). This confirms that the Pacific group is the origin of the Dwarf varieties.

\subsection{Molecular diversity among Dwarfs}

Molecular markers are useful to identify genetic relationships among varieties. Since Dwarfs breed true -to type, they allow inference of the origin of introduced varieties. The percentage of missing data in our Dwarf diversity study was 1.14 on average. A total of 56 alleles (4.31 per locus) were detected. Only two varieties, Malayan Green Dwarf (MGD) and Catigan Green Dwarf (CATD) were notably polymorphic. The other 26 had an average heterozygosity of $0.69 \%$ and only 1.07 alleles per locus.

The distances along the horizontal branches of the dendrogram presented in figure 4 approximate the number of allele substitutions between varieties (see scale). Distances smaller than 1 correspond to essentially identical molecular profiles, differing only in residual polymorphism. The majority of the 14 varieties found in the upper part of the dendrogram are from South-East Asia. This suggests that the remaining three, found in Brazil, India (Gangabondam) and in Micronesia (the Marshall Islands) were introduced from South-east Asia. There is geographical sub-structure within South-east Asia: an Indonesian variety (Salak) and three Malaysian varieties (Yellow, Red and Green) cluster, as do the three varieties from the Philippines (Catigan, Tacunan and Pilipog). Varieties from Thailand and Vietnam form a different cluster. 
The lower part of the dendrogram forms a more diverse group comprising mostly varieties from the South Pacific. Dwarf from Nicaragua and the Mangipod (Philippines) appear to have a South Pacific origin. Six varieties are intermediate: two green varieties found in India and Sri Lanka and four varieties with red or orange fruits. Based on name similarities, the Pemba Dwarf (locally called Kitamli) (Krain et al. 1994) might be derived from the King coconut (or Rath Thembili) with progeny moved later to Cameroon, which was also under German colonization. Another possibility is that all these varieties originated from Papua New Guinea or from the Solomon Islands (also former German possessions).

\subsection{Height and bole character}

In the Bandiripuwa $\mathrm{F}_{2}$ trial, we observed 32, 42 and 16 palms respectively with no bole, low bole and high bole. This is not precisely the expected 1:2:1 proportion for a co-dominant major gene $(\chi 2=6.08 \mathrm{p}$-value $=0.047)$. However, the moderate bias in favour of palms with no bole could be accounted for by involuntary selection in nursery (Dwarfs tend to germinate early). This suggests that the presence of a bole could result from a single codominant locus and the data are consistent with the $\mathrm{F}_{1}$ being of the type "Bb" with allele " $\mathrm{B}$ " contributed by the Tall parent and "b" by the Sri Lanka Green Dwarf. There is little difference between the heights of palms with a low bole (mean $9.58 \mathrm{~m}$, sd $2.11 \mathrm{~m}$ ) and high bole (mean $9.48 \mathrm{~m}$, sd $2.85 \mathrm{~m}$ ). The palms with no bole are on average $1 \mathrm{~m}$ smaller (mean height $8.38 \mathrm{~m}$, sd $2.12 \mathrm{~m}$ ). However this difference was not statistically significant $(F=2.75$, p-value $=0.065)$, indicating a large overlap among bole categories for height, as can seen in figure 5. There is thus no strong association between the presence of a bole and height. This confirms that the presence of a bole and the height depend on different genes. In addition, the distribution of height (figure 5) shows two modes, one between $8 \mathrm{~m}$ and $9 \mathrm{~m}$ and one between $11 \mathrm{~m}$ and $12 \mathrm{~m}$. This suggests that height too depends on a major gene. However other factors, genetic and environmental, also contribute, making it difficult to assign individuals to a definite genotype.

\section{Discussion}

\subsection{Neutral markers and the geographic origin of Dwarfs}

SSR studies show that most Dwarf varieties are predominantly homozygous. Here, only four out of 42 Dwarfs (NLAD excluded), were substantially heterozygous and nine others were heterozygous at only one or two loci. This confirms the results of previous studies (Lebrun, Grivet et al., 1998; Perera et al., 1999; Teulat et al., 2000; Gunn et al., 2011). This can be explained both by the predominant self-pollinating habit observed in Dwarfs and by selection of true-to-type palms by the farmers.

Dwarfs form a homogeneous genetic group and their overall allele richness is lower than Talls. This is also reflected in a decrease in overall genetic diversity (Nei, 1987); 0.374 in Dwarfs and 0.703 in Talls (Perera et al., 2003). The Dwarf type has its origin in the Pacific ecogeographic region; the degree of differentiation $\left(F_{S T}\right)$ between Talls and Dwarfs was lowest in the Philippines (0.21) followed by Indonesia (0.36) and highest in Sri Lanka (0.51). In addition, allelic diversity is lower in Sri Lanka than in the two other countries. This is a strong indication of an origin in the Pacific group and more specifically in Southeast Asia as previously proposed by Gunn et al. (2011), Rohde et al. (1995), Lebrun et al. (1998). 
In spite of the overall homogeneity of Dwarfs, variation among them still showed geographic structure, making it possible to distinguish Dwarfs from Southeast Asia and from South Pacific, and at the country level, Malaysia and the Philippines. Due to their autogamy, it is also possible to trace recently introduced varieties to their region of origin. Finally, Dwarfs from the South Pacific appear to be more diverse than those from Southeast Asia, suggesting a secondary diversification event.

\subsection{A single domestication event}

The reduced diversity in Dwarfs is a signature of a population bottleneck. We suggest that this is a consequence of the mutation of a major gene in a Tall individual resulting in the female flowering phase occurring earlier and lasting longer. As a result, in Dwarfs, female and male flowering concur, strongly favouring self-pollination (Rognon, 1976, Sangaré et al., 1978). This tendency is reinforced by the fact, observed by Sangare (1981), that the stigmas of Dwarf palms are more receptive to Dwarf pollen than to Tall pollen. This resulted in the development of several inbred lines in which a number of rare alleles would have been fixed by chance, even if unlinked to the initial mutation. Once fixed, these inbred lines would have expressed these traits consistently, allowing farmers to select directly or indirectly for desirable traits such as slow growth, bright fruit colour, sweet nut water and early nut bearing.

However, autogamy is also unfavourable because of inbreeding depression among progeny. Similarly, slow growth and a short life span make Dwarfs poor competitors in natural conditions. This explains why they are rarely found except close to habitation; where they are protected by farmers. In other words, the very existence of Dwarf coconuts demanded artificial selection and they represent the most advanced stage of coconut domestication. In comparison, Tall coconuts can be described as an incipient domesticate (Clement et al., 2010): they are almost always cultivated and the imprint of human selection is perceptible to various degrees according to variety (Harries, 1978). However, Talls remain viable without cultivation, as shown by the examples of the Cocos (Keeling) Islands or the pre-Colombian coconuts of Panama (Baudouin et al., 2014).

Among the traits selected by farmers, some are directly useful, such as sweet nut water, early nut bearing and reduced height growth. Other traits, although not useful in themselves, make the selection of desirable traits easier. This is the case for the bright colour seen on the fruits, petioles and germs in many Dwarfs. This trait is still used as an early selection criterion in Dwarf as well as in $F_{1}$ hybrid seedling production (De Nucé De Lamothe and Rognon, 1973). Self-pollinating variants probably remained unnoticed by farmers until several of these traits were combined in the same genotype. Such a conjunction of inbreeding, useful traits and human selection is a rare event and must have occurred only once, resulting in all Dwarfs sharing a large proportion of their genome. This is further confirmed by the fact that the genome size is uniform in Dwarfs, whereas limited but significant variations are observed in Talls (Gunn et al., 2015).

It is too early to assign a date to this domestication event. However, the observations of Swaminathan and Nambiar (1961) on meiosis abnormalities - a manifestation of inbreeding depression - suggests that it is relatively recent, at least in terms of number of generations. In fact, the rate of chromosomal abnormality and gamete abortion, high in self-pollinated Talls (cumulated abnormalities $75 \%$ in the apricot Tall), is still large in Dwarfs (8\% to 38\% 
according to the type). Further research with suitable genetic data and coalescent simulations would make it possible to infer the date, the number of lines and the genotypes of the ancestral Dwarf population.

\subsection{Overall stability of the Dwarf genome}

There is an apparent paradox: Dwarfs and Talls co-exist throughout the coconut cultivation area, are interfertile, yet behave as essentially distinct gene pools. The Dwarf phenotype depends on several genes. Although the presence of a bole and height appear to depend on a single locus, other traits such as flowering pattern, delay in flowering and fruit colour appear to segregate independently. Intermediate phenotypes are, however, extremely rare (with a few exceptions such as rare self-pollinating "semi-Talls" and the Tagnanan Green Dwarfs, which have a bole).

The Dwarf gene pool would not have remained stable without continuous selection by farmers on several traits at an early stage of their domestication to select true-to-type progenies. In this view, the practice, noted in India, of retaining the rare hybrid progenies of Dwarf palms, known as Enum thirinjathuin, or naturally crossed Dwarfs (Bourdeix et al., 2008) would be relatively recent and possibly influenced by modern breeding practices. Regarding the Tall gene pool, the small proportion (about 5\%, Bourdeix et al., 2001) of admixture from Dwarfs is sufficient to ensure that Dwarf contribution is minimal and virtually unnoticeable.

\subsection{Causes of diversification among Dwarfs}

The narrow genetic diversity of Dwarfs observed with molecular markers (RFLP, SSR) suggests a common origin in South-East Asia. Nevertheless, a small number of visible traits (colour, fruit shape, morphology), show striking diversity among varieties. The causes of this diversity are probably multiple: (i) The first self-pollinating individuals were heterozygous and continuing inbreeding resulted in a large number of diversified pure lines among which the farmers selected their preferred varieties based on suitability and distinctness. In other words, diversifying selection was applied on visual traits, (ii) Mutation also contributed to diversification. (iii) Tall coconuts planted near habitations were more likely than others to be pollinated by Dwarfs. While the phenotype of a $F_{1}$ coconut tends toward the Tall type, this process may be repeated, resulting in successive backcrosses onto Dwarfs. Among these advanced generations, self-pollinating palms with dwarfish phenotypes may eventually reappear and be adopted by farmers as new varieties. This must be rare, otherwise molecular data would reveal systematic gene flow between Dwarfs and Talls from the same region, which is not the case. However, this seems to have occurred at least once in the South Pacific, possibly in Papua New Guinea and this would explain the higher diversity observed among the Dwarfs found in the South Pacific (Figure 4). A similar mechanism could also account for a small number of "semi-Talls" or of Dwarfs presenting a bole at the base of the stem: the Talasea Red Tall, the King coconut in South Asia and the Tacunan Green Dwarf, but one cannot exclude that these traits existed in the initial set of pure lines. (iv) Crosses between Dwarf varieties may have generated more varieties. This could be the case of a group of varieties known collectively as coconiño (Catigan, Pilipog etc.) in the Philippines, which have in common relatively small rounded nuts, are green in colour and are early bearing. 


\section{Conclusions}

Based on our results, the Dwarf phenotype appears to result from domestication. The triggering event was the appearance of autogamy which, after a few generations, resulted in fixed lines each incorporating a random subset of the alleles of the ancestral Tall population. This allowed the farmers to select and reproduce their preferred genotypes faithfully. Most of these fixed lines would have disappeared, eliminated by natural selection and/or discarded by farmers. Only genotypes presenting desirable traits such as slow growth, early fruit set and attractive fruit characteristics (especially good drinking water in immature fruits) were retained by farmers to be planted close to their habitations. This selection was made effective by using phenotypic markers such as petiole colour; an indirect method of selection for quality. It also led to the establishment of Dwarfs as a distinct gene pool. However, recombination between Dwarf and Talls remains possible, as shown by the existence of a small number of intermediate forms.

The increasing interest in coconut water has made commercial plantation of Dwarfs more profitable. However, this incurs a high risk due to their narrow genetic base. For example, pathogens may evolve considerably faster. The resurgence of Lethal yellowing in Jamaica is an example (Lebrun et al 2008). Broadening the diversity of Dwarfs would reduce this risk by favoring multifactorial disease resistance, reducing the probability of selection of virulent pathogen strains.

A radical solution would be to reselect entirely new Dwarf genotypes from $\mathrm{F}_{2}$ crosses. Given that the Dwarf phenotype is controlled by several independent genes, this task would involve multiple generations of selection and back-crossing. This is probably impractical without the assistance of appropriate genomic tools.

\section{Acknowledgements}

Dr. (Miss) S A C N Perera and Mr. N Hearth of the Coconut Research Institute of Sri Lanka are acknowledged for their support in data collection from $\mathrm{F}_{2}$ population.

\section{References}

Baudouin, L., Gunn, B.F. and Olsen, K.M. 2014. The presence of coconut in southern Panama in pre-Columbian times: clearing up the confusion. Annals of Botany 113:15.

Baudouin, L., Lebrun, P., Konan, J.-L., Ritter, E., Berger, A. and Billotte, N. 2006. QTL analysis of fruit components in the progeny of a Rennell Island Tall coconut (Cocos nucifera L.) individual. Theoretical and applied genetics 112:258-268.

Bourdeix, R. 1988. Etude du déterminisme génétique de la couleur du germe chez le cocotier Nain. Oléagineux 43:371-375.

Bourdeix, R., Baudouin, L., Billotte, N., Labouisse, J.-P. and Noiret, J.-M. 2001. Coconut. p. 106-127. In: A. Charrier, M. Jacquot, S. Hamon and D. Nicolas (eds.), Tropical plant breeding. CIRAD, Montpellier.

Bourdeix, R., Leclerc, C., Thampan, P.K., Baudouin, L. and Joly, H.I. 2008. Modern and natural coconut hybrids in southern India : Natural, technical and social facts. Journal of ethnobiology 28:39-54.

Bourdeix, R., N'Cho, Y.P., Lesaint, J.P. and Sangaré, A. 1990. Une stratégie de sélection du cocotier Cocos nucifera L. I. Synthèse des acquis. Oléagineux 45:359-371. 
Clement, C., De Cristo-Araújo, M., Coppens D’Eeckenbrugge, G., Alves Pereira, A. and Picanço-Rodrigues, D. 2010. Origin and Domestication of Native Amazonian Crops. Diversity 2:72.

De Nucé De Lamothe, M. and Rognon, F. 1973. La production de semences hybrides chez le cocotier. Exploitation des champs semenciers. Oléagineux 28:287-291.

Fernando, W.M.U. and Perera, L. 1997. Evaluation of genotypes arising from $\mathrm{F}_{2}$ generation segregations in Dwarf x Tall crosses of Cocos nucifera. CORD XIII:26-33.

Gunn, B.F., Baudouin, L., Beulé, T., Ilbert, P., Duperray, C., Crisp, M., Issali, A., Konan, J.L. and Rival, A. 2015. Ploidy and domestication are associated with genome size variation in Palms. American Journal of Botany 102:1625-1633.

Gunn, B.F., Baudouin, L. and Olsen, K.M. 2011. Independent Origins of Cultivated Coconut (Cocos nucifera L.) in the Old World Tropics. PLoS One 6:e21143.

Harries, H.C. 1978. The evolution, dissemination and classification of Cocos nucifera L. The botanical review 44:265-319.

Krain, E., Issa, J.A., Kullaya, A. and Harries, H.C. 1994. The Coconut Palm in East Africa. 2. The Pemba Dwarf in Zanzibar. Principes 38:138-141.

Lebrun, P., N'Cho, Y.P., Seguin, M., Grivet, L. and Baudouin, L. 1998. Genetic diversity in coconut (Cocos nucifera L.) revealed by restriction fragment length polymorphism (RFLP) markers. Euphytica:103-108.

Menon, K.P.V. and Pandalai, K.M. 1958. The coconut. A Monograph. Indian Central Coconut Committee,.

Nei, M. 1987. Molecular evolutionary genetics. Columbia university press.

Ninan, C.A. and Satyabalan, K. 1964. A Study of Natural, Self and Cross (Dwarf $\times$ Tall) Progenies of Dwarf Coconuts of the West Coast of India and its Bearing on the Genetics of Dwarfs and the Putative Hybridity of their Off-Type Progenies. Caryologia 17:77-91.

Perera, L., Russell, J.R., Provan, J. and Powell, W. 1999. Identification and characterization of microsatellite loci in coconut (Cocos nucifera L.) and the analysis of coconut populations in Sri Lanka. Molecular Ecology 8:335-346.

Perera, L., Russell, J.R., Provan, J. and Powell, W. 2003. Studying genetic relationships among coconut varieties/populations using microsatellite markers. Euphytica 132:121-128.

Perrier, X. and Jacquemoud-Collet, J.P. 2006. DARwin software http://darwin.cirad.fr/darwin.

Purseglove, J.W. 1985. Tropical Crops: Monocotyledons. Longman, London.

Rognon, F. 1976. Biologie florale du cocotier. Durée et succession des phases mâles et femelles chez divers types de cocotiers. Oléagineux 31:13-18.

Rohde, W., Kullaya, A., Rodriguez, J. and Ritter, E. 1995. Genome analysis of Cocos nucifera L. by PCR amplification of spacer sequences separating a subset of copialide EcoRI repetitive elements. J. Genet. \& Breed. 49:179-186.

Sangaré, A. 1981. Compétition pollinique et légitimité des semences produites dans les champs semenciers de cocotiers. Oléagineux 36:424-427.

Sangaré, A., Rognon, F. and Nucé de Lamothe, M.d. 1978. Les phases mâles et femelles de l'inflorescence du cocotier. Influence sur le mode de reproduction. Oléagineux 33:609-617.

Santos, G.A., Batugal, P.A., Othman, A., Baudouin, L. and Labouisse, J.-P. 1996. Manual on standardized research techniques in coconut breeding. IPGRI, Rome. 
Swaminathan, M.S. and Nambiar, M.C. 1961. Cytology and origin of the Dwarf Coconut Palm. Nature 192:85-86.

Teulat, B., Aldam, C., Trehin, R., Lebrun, P., Barker, J.H.A., Arnold, G.M., Karp, A., Baudouin, L. and Rognon, F. 2000. An analysis of genetic diversity in coconut (Cocos nucifera) populations from across the geographic range using sequence-tagged microsatellites (SSRs) and AFLPs. Theoretical and Applied Genetics 100:764-771.

Table 1: List of Dwarf cultivars used in the diversity study with elementary statistics

\begin{tabular}{llllll} 
Variety Name & CORD & $\begin{array}{l}\text { Number } \\
\text { s }\end{array}$ & $\begin{array}{l}\text { Missing } \\
\text { data } \%\end{array}$ & $\begin{array}{l}\text { Heterozygosit } \\
\text { y } \%\end{array}$ & $\begin{array}{l}\text { Alleles } \\
\text { per locus }\end{array}$ \\
\hline Aromatic Green Dwarf & AROD & 8 & 0 & 0 & 1 \\
Brazilian Green Dwarf & BGD & 19 & 2.02 & 0 & 1 \\
Catigan Green Dwarf & CATD & 6 & 0 & 12.82 & 1.31 \\
Chowghat Green Dwarf & CGD & 4 & 0 & 1.92 & 1.08 \\
Chowghat Orange Dwarf & COD & 5 & 0 & 1.54 & 1.08 \\
Cameroon Red Dwarf & CRD & 5 & 0 & 0 & 1 \\
Gangabondam Green Dwarf & GGBD & 4 & 0 & 0 & 1 \\
Gazelle Red & GPTr & 4 & 9.62 & 0 & 1 \\
Malayan Green Dwarf & MGD & 5 & 0 & 23.08 & 1.85 \\
Mangipod Green Dwarf & MGPD & 5 & 0 & 0 & 1 \\
Marshall Islands Green Dwarf & MIGD & 14 & 3.30 & 0.57 & 1.08 \\
Malayan Red Dwarf & MRD & 11 & 0.70 & 2.11 & 1.31 \\
Malayan Yellow Dwarf & MYD & 68 & 0.45 & 0.68 & 1.54 \\
Nicaragua Green Dwarf & NICD & 4 & 0 & 0 & 1 \\
Sri Lanka Green Dwarf & PGD & 22 & 2.80 & 1.44 & 1.38 \\
Pilipog Green Dwarf & PILD & 4 & 0 & 0 & 1 \\
Pemba Red Dwarf & PRD & 6 & 0 & 2.56 & 1.08 \\
PNG Yellow Dwarf & PYD & 2 & 0 & 3.85 & 1.08 \\
Rabaul Red Dwarf & RARD & 2 & 0 & 0 & 1 \\
Raja Brown Dwarf & RBD & 12 & 0 & 0 & 1.08 \\
King Coconut & RTB & 2 & 0 & 0 & 1 \\
Salak Green Dwarf & SKD & 5 & 0 & 0 & 1 \\
Tacunan Green Dwarf & TACD & 5 & 3.08 & 3.17 & 1.15 \\
Thailand Green Dwarf & THD & 10 & 8.46 & 0 & 1 \\
Tahiti Red Dwarf & TRD & 5 & 0 & 0 & 1 \\
Talasea Red Tall & TRT & 2 & 0 & 0 & 1 \\
Vanuatu Red Dwarf & VRD & 5 & 1.54 & 0 & 08 \\
Xiem Green Dwarf & XGD & 2 & 0 & 0 & 1 \\
\hline
\end{tabular}


Table 2: Allele frequencies at 12 microsatellite loci in the world wide collection of coconut genotypes studied. Most common allele at each locus is shown in bold.

\begin{tabular}{|c|c|c|c|c|c|c|c|}
\hline \multirow[b]{2}{*}{ Locus } & \multirow{2}{*}{$\begin{array}{l}\text { Allele } \\
\text { (bp) }\end{array}$} & \multicolumn{3}{|c|}{ Frequency } & \multirow{2}{*}{$\begin{array}{l}\text { Allele } \\
\text { (bp) }\end{array}$} & \multicolumn{2}{|c|}{ Frequency } \\
\hline & & Tall & Dwarf & Locus & & Tall & Dwarf \\
\hline \multirow[t]{9}{*}{ CAC2 } & 210 & 0.007 & - & CAC3 & 187 & 0.027 & - \\
\hline & 220 & 0.007 & - & & 197 & 0.623 & 0.963 \\
\hline & 232 & 0.061 & - & & 199 & 0.226 & 0.037 \\
\hline & 234 & 0.142 & - & & 201 & 0.116 & - \\
\hline & 240 & 0.270 & 0.038 & & 203 & 0.007 & - \\
\hline & 246 & 0.061 & 0.094 & & & & \\
\hline & 248 & 0.128 & 0.057 & & & & \\
\hline & 252 & 0.034 & 0.057 & & & & \\
\hline & 254 & 0.291 & 0.755 & & & & \\
\hline \multirow[t]{9}{*}{$\mathrm{CAC} 4$} & 182 & 0.007 & - & CAC6 & 150 & 0.033 & - \\
\hline & 186 & 0.314 & 0.462 & & 152 & 0.155 & - \\
\hline & 188 & 0.193 & 0.077 & & 154 & 0.101 & 0.009 \\
\hline & 200 & 0.036 & - & & 156 & 0.020 & - \\
\hline & 204 & 0.186 & - & & 158 & 0.304 & 0.273 \\
\hline & 208 & 0.193 & - & & 160 & 0.277 & 0.672 \\
\hline & 212 & 0.064 & 0.462 & & 162 & 0.081 & 0.009 \\
\hline & 216 & 0.007 & - & & 164 & 0.014 & 0.036 \\
\hline & & & & & 168 & 0.014 & - \\
\hline \multirow[t]{9}{*}{ CAC8 } & 188 & 0.050 & 0.020 & CAC10 & 195 & 0.007 & - \\
\hline & 196 & 0.014 & - & & 197 & 0.188 & - \\
\hline & 198 & 0.130 & 0.830 & & 201 & 0.542 & 0.917 \\
\hline & 200 & 0.210 & 0.080 & & 203 & 0.243 & 0.074 \\
\hline & 202 & - & 0.020 & & 205 & 0.021 & 0.009 \\
\hline & 204 & 0.113 & 0.047 & & & & \\
\hline & 206 & 0.010 & - & CAC13 & 158 & 0.423 & 0.833 \\
\hline & 208 & 0.040 & - & & 162 & 0.570 & 0.167 \\
\hline & 210 & 0.430 & - & & 172 & 0.007 & - \\
\hline
\end{tabular}


Table 2 (continued)

\begin{tabular}{|c|c|c|c|c|c|c|c|}
\hline \multirow{2}{*}{ Locus } & \multicolumn{4}{|c|}{ Frequency } & \multicolumn{3}{|c|}{ Frequency } \\
\hline & $\begin{array}{l}\text { Allele } \\
\text { (bp) }\end{array}$ & Tall & Dwarf & Locus & $\begin{array}{l}\text { Allele } \\
\text { (bp) }\end{array}$ & Tall & Dwarf \\
\hline \multirow[t]{7}{*}{ CAC20 } & 122 & 0.007 & - & CAC52 & 148 & 0.097 & - \\
\hline & 130 & 0.021 & - & & 150 & 0.014 & 0.028 \\
\hline & 132 & 0.479 & 0.204 & & 154 & 0.021 & - \\
\hline & 134 & 0.211 & 0.019 & & 156 & 0.313 & 0.037 \\
\hline & 136 & 0.197 & 0.148 & & 158 & 0.069 & - \\
\hline & 138 & 0.085 & 0.629 & & 160 & 0.389 & 0.935 \\
\hline & & & & & 162 & 0.097 & - \\
\hline \multirow[t]{13}{*}{ CAC56 } & 144 & 0.169 & - & CAC65 & 154 & 0.264 & 0.500 \\
\hline & 146 & 0.014 & - & & 156 & 0.223 & 0.083 \\
\hline & 150 & 0.007 & 0.009 & & 164 & 0.034 & - \\
\hline & 152 & 0.155 & 0.066 & & 168 & 0.142 & - \\
\hline & 154 & 0.007 & - & & 170 & 0.237 & - \\
\hline & 156 & 0.134 & - & & 176 & 0.095 & 0.417 \\
\hline & 158 & 0.121 & 0.189 & & 180 & 0.007 & - \\
\hline & 160 & 0.197 & 0.293 & CAC68 & 136 & 0.089 & 0.887 \\
\hline & 164 & 0.070 & 0.009 & & 140 & 0.007 & - \\
\hline & 166 & 0.092 & 0.434 & & 146 & 0.630 & 0.113 \\
\hline & 168 & 0.035 & - & & 148 & 0.007 & - \\
\hline & & & & & 150 & 0.253 & - \\
\hline & & & & & 152 & 0.014 & - \\
\hline
\end{tabular}


Figure 1: Bole ranking based on size shape and height

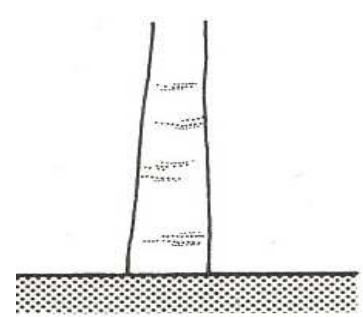

No bole

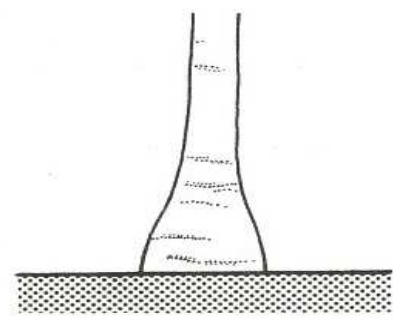

Small bole

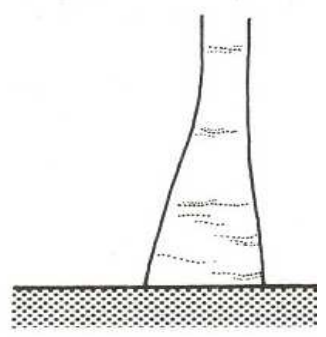

Large bole

Figure 2: Allele distribution of Tall and Dwarf at locus CAC2. Note the loss of allelic richness of Dwarfs. (X axis is the allele frequency)

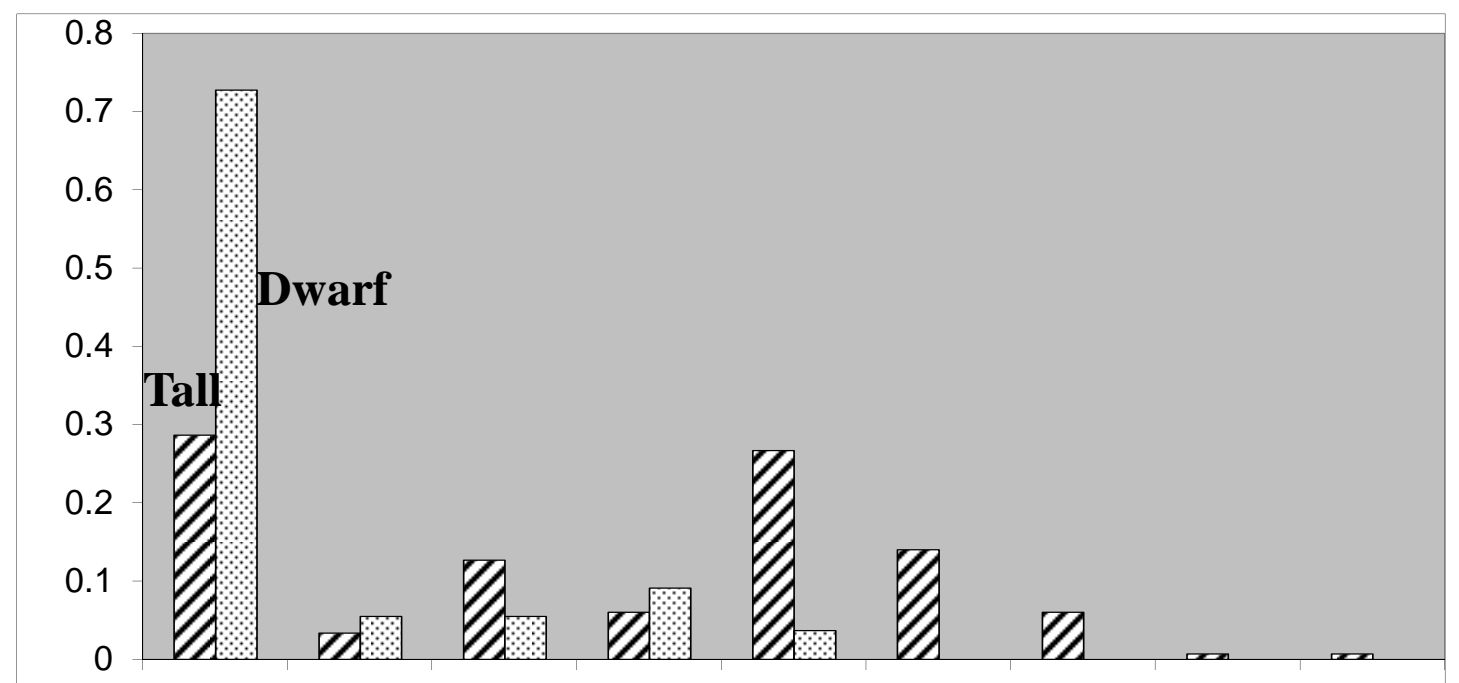


Figure 3. UPGMA phenogram showing the relationships between individuals based on proportion of shared alleles ( $\left.\mathrm{D}_{\mathrm{PS}}\right)$ (SEA: Southeast Asia, SA: South Asia) Modified after Perera, et al., 2003.

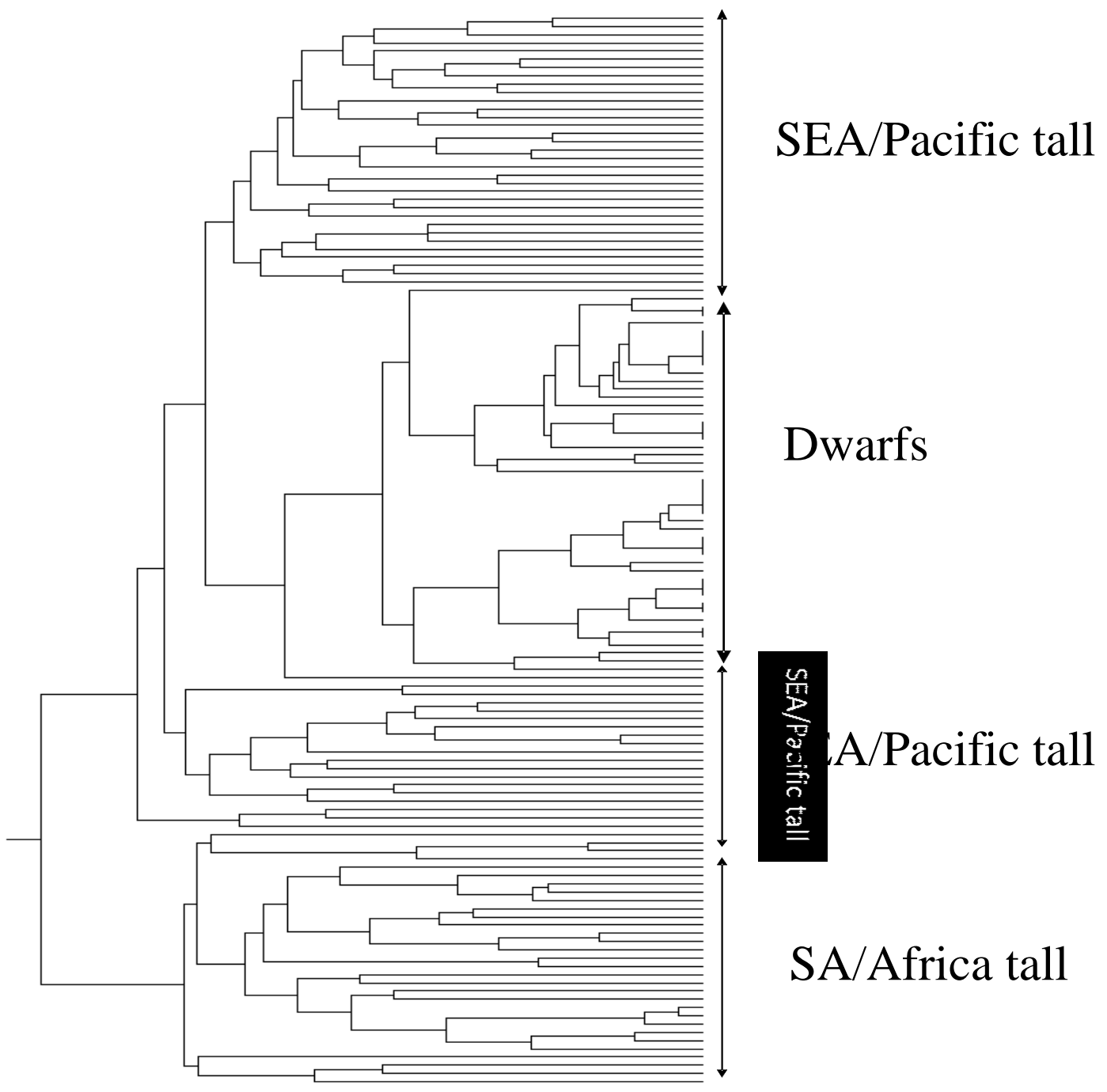


Figure 4: Neighbour-joining tree of the Dwarf cultivars

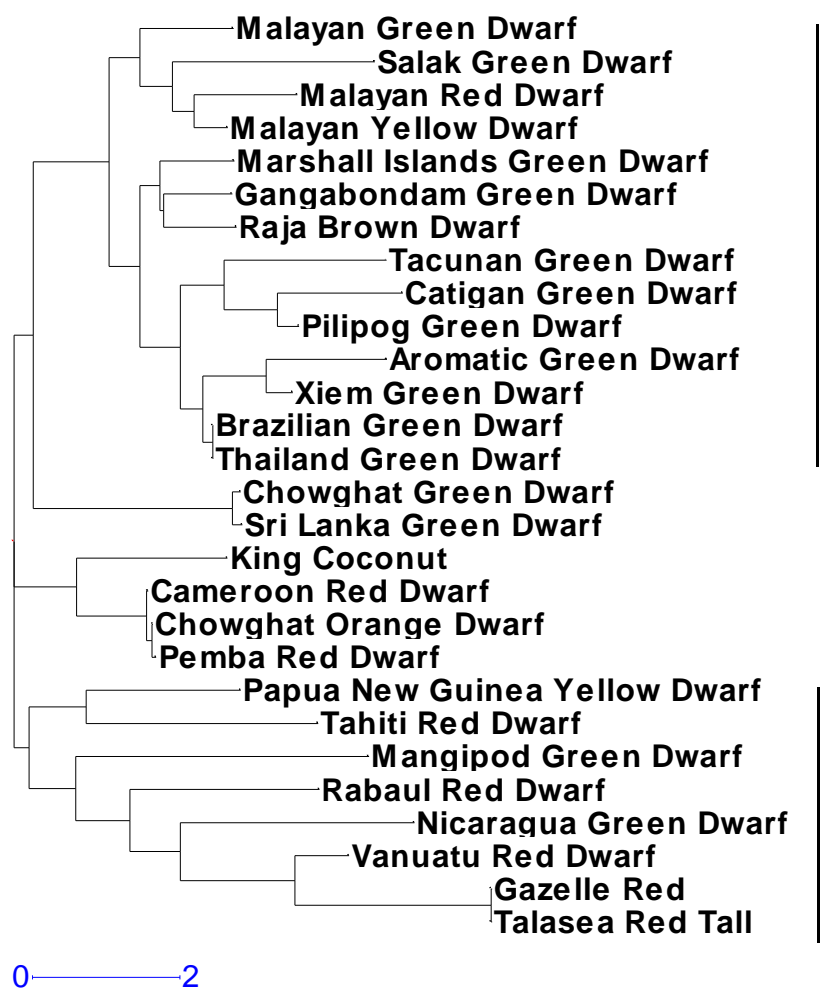

South-East Asian type

Pacific type 
Figure 5: Height distribution of $F_{2}$ between Dwarf $x$ Tall and association of bole character

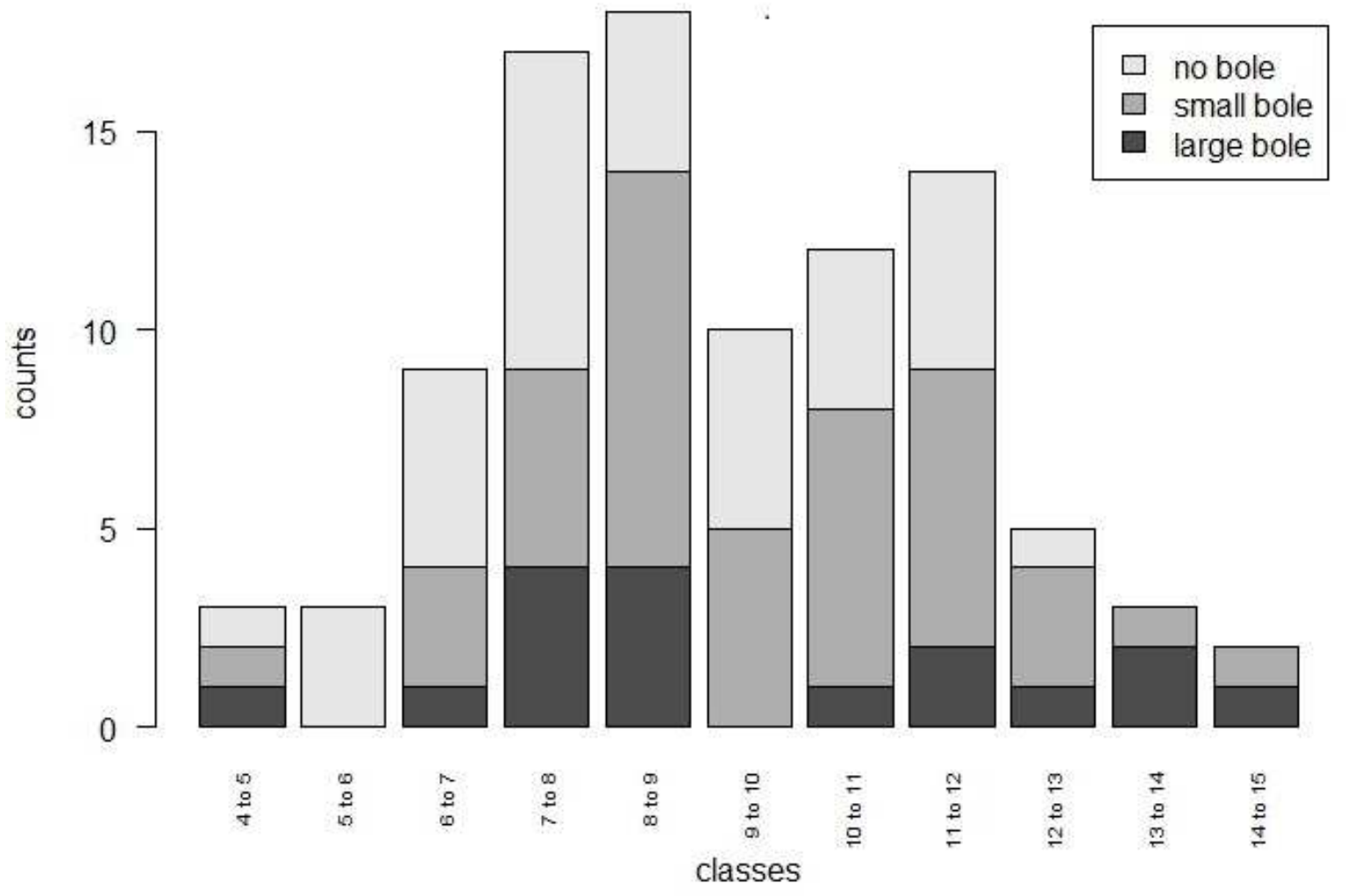

